\title{
Modelo analítico da pedagogia do oprimido: sistematização do método Paulo Freire
}

\author{
Ramon Rodrigues Ramalho'
}

\section{RESUMO}

Este artigo descreve os elementos característicos da pedagogia do oprimido, destacando as mediações pedagógicas centrais envolvidas no chamado método de Paulo Freire, que é sistematizado como um modelo analítico no final do texto. Para tal, centramo-nos nas experiências sociopedagógicas desenvolvidas pelos movimentos sociais, entendendo-as como estratégias de formação. O estudo aqui apresentado é o resultado de mais de quinze anos de investigação acadêmica, com movimentos sociais do Brasil e da Argentina. Nessa perspectiva, realizamos uma revisão bibliográfica da obra central de Freire, Pedagogia do oprimido, aqui apresentada em duas partes: o complexo do oprimido e o circuito dialógico, como leitura sintética que oferecemos da proposta pedagógica de Freire. O objetivo é desenvolver um conhecimento mais abrangente sobre esses processos de formação, promover as experiências educativas dos movimentos sociais e difundir o pensamento de Paulo Freire.

\section{PALAVRAS-CHAVE}

Paulo Freire; pedagogia do oprimido; movimentos sociais; circuito dialógico; temas geradores; invasão cultural.

'Universidad de Buenos Aires, Buenos Aires, Argentina. 


\title{
ANALYTICAL MODEL OF THE PEDAGOGY OF THE OPPRESSED: SYSTEMATIZATION OF THE PAULO FREIRE'S METHOD
}

\begin{abstract}
This article describes the characteristic elements of the pedagogy of the oppressed, highlighting the key pedagogical mediations involved in the socalled Paulo Freire's Method, which is systematized as an Analytical Model at the end of the text. To do so, we have focused on the socio-pedagogical experiences developed by social movements, understanding them as strategies of formation. This study is the result of more than fifteen years of academic investigation along with social movements from Brazil and Argentina. From this perspective, we conducted a bibliographic review of Freire's major work, Pedagogy of the oppressed, herein described in two parts: the Complex of the Oppressed and the Dialogical Circuit, as a synthetic reading offered of Freire's pedagogical proposal. Our objective is to develop a more comprehensive knowledge about these formation processes, promoting the educational experiences of the social movements, and spread Paulo Freire's thinking.

KEYWORDS

Paulo Freire; Pedagogy of the oppressed; social movements; Dialogical Circuit; generative themes; cultural invasion.
\end{abstract}

\section{MODELO ANALITICO DE LA PEDAGOGÍA DEL OPRIMIDO: SISTEMATIZACIÓN DEL MÉTODO PAULO FREIRE}

\section{RESUMEN}

Este artículo describe los elementos característicos de la Pedagogía del Oprimido, resaltando las mediaciones pedagógicas centrales involucradas en el llamado Método Paulo Freire, sistematizado como un Modelo Analítico al final del texto. Para ello, nos enfocamos en las experiencias sociopedagógicas desarrolladas por los movimientos sociales, entendiéndolas como estrategias de formación. El estudio aquí presentado es el resultado de más de quince años de investigación académica junto a movimientos sociales de Brasil y Argentina. Desde esta perspectiva, realizamos una revisión bibliográfica de la obra central de Freire, Pedagogía del Oprimido, presentada aquí en dos partes: el Complejo del Oprimido y el Circuito Dialógico, en tanto síntesis que ofrecemos de la propuesta pedagógica de Freire. Nuestro objetivo es contribuir a un conocimiento más amplio sobre estos procesos formativos, promoviendo las experiencias educativas de los movimientos sociales y difundir el pensamiento de Freire.

PALABRAS CLAVE

Paulo Freire; Pedagogía del Oprimido; movimientos sociales; Circuito Dialógico; temas generadores; invasión cultural. 


\section{INTRODUÇÃO}

Paulo Freire (1921-1997) é um dos mais renomados intelectuais brasileiros e um dos mais proeminentes pedagogos do mundo pós-guerra, embora alguns setores políticos questionem atualmente sua nomeação como patrono da educação brasileira (2012), colocando-o no centro de uma disputa ideológica em seu país natal ${ }^{1}$. Ainda assim, seu trabalho continua sendo uma referência indispensável em muitas universidades. Ele também desempenha um papel central nas experiências socioeducativas desenvolvidas pelos movimentos sociais latino-americanos no século XXI, uma vez que a história da educação popular, no Brasil, entrelaça-se com a sua biografia (Elisalde, 2013; Torres, 2017).

Este estudo é resultado de mais de 15 anos de investigação acadêmica entre movimentos sociais do Brasil e da Argentina, particularmente em colaboração com o Núcleo de Estudos sobre o Trabalho Humano da Universidade Federal de Minas Gerais (NESTH/UFMG) no Brasil e o Centro de Estudios e Investigaciones Laborales (CEIL/CONCIET), na Argentina. Nossa pesquisa foi desenvolvida entre diferentes populações em situação de vulnerabilidade social, como garimpeiros, comunidades de favelas, camponeses sem-terra brasileiros e fábricas argentinas recuperadas por seus trabalhadores, uma vez abandonadas pelos seus antigos patrões ${ }^{2}$ (Ramalho, 2011; 2019).

Durante a nossa pesquisa, desenvolvemos diversos processos socioeducativos de alfabetização comunitária e educação cívica, ao mesmo tempo em que fomentamos projetos de geração de renda, além de acompanhar a ocupação de terras abandonadas no Brasil e de fábricas na Argentina. No decorrer desses processos socioeducativos, confrontamo-nos com momentos em que diferentes aspectos emergentes na formação do grupo exigiam uma explicação. A investigação muitas vezes encontrou apoio, para entender o que estava acontecendo, nos escritos de Paulo Freire sobre a luta entre a subjetividade do oprimido e a do opressor em um grupo em formação.

Por isso, o trabalho de Paulo Freire era, frequentemente, requerido pelos pesquisadores para responder a essas questões emergentes, uma vez que ele nos fornece variadas chaves analíticas para entender os processos formativos em que nós — os/as pesquisadores/as - nos encontrávamos imersos. Ao articular os diferentes momentos que vivemos por meio desses processos socioeducativos, podemos agora apresentar uma sistematização do chamado método Paulo Freire de Educação - a pedagogia do oprimido.

1 Em 2016, o Pedagogia do oprimido foi o único livro brasileiro na lista dos 100 livros mais pedidos pelas universidades de língua inglesa $(\mathrm{G} 1,2016)$. Apesar disso, muitos meios de comunicação questionam a validade do trabalho de Paulo Freire (Cerioni, 2019), enquanto alguns setores políticos estão empenhados em retirar sua nomeação como patrono da educação brasileira (Ortega, 2019).

2 A sistematização aqui apresentada foi, primeiramente, elaborada como parte da pesquisa de doutorado do autor e, posteriormente, desenvolvida como parte de sua pesquisa de pós-doutorado. 
Neste trabalho, apresentamos uma leitura sintética dos elementos característicos da pedagogia do oprimido - também conhecido como método Paulo Freire de Educação - com foco nos processos pedagógicos desenvolvidos pelos movimentos sociais. Nosso exame terá, como chave analítica, a compreensão das experiências socioeducativas dos movimentos sociais, considerando-as como estratégias de formação desenvolvidas para que as populações, em diferentes situações de vulnerabilidade social, possam emergir como sujeitos coletivos que reagem e se tornam protagonistas de sua própria história. Nessa perspectiva, realizamos uma revisão bibliográfica do trabalho central de Freire, Pedagogia do oprimido (1987), destacando os dispositivos pedagógicos (Figari, 2015) que caracterizam a ação cultural antidialógica e aqueles correspondentes à pedagogia dialógica, em favor da qual ele advoga.

Com esse foco, podemos ver a pedagogia do oprimido como uma disputa entre estratégias de formação do opressor e do oprimido. Embora as classes populares tenham sua própria cultura, dotada de uma rica e complexa visão de mundo, a estrutura opressora impõe seus padrões culturais às populações oprimidas, levando-as a hospedar em si o opressor como modelo ideal da humanidade e a adotar padrões culturais externos como próprios, com o propósito adaptativo de se integrar à estrutura opressora. A pedagogia do oprimido constitui-se na interação entre a invasão cultural, que leva à imersão da consciência, e o processo de investigação dos temas-geradores que leva, como veremos, à emersão da consciência oprimida. Em suma, a pedagogia do oprimido move-se na oposição entre os polos constituídos pela imersão e pela emersão das consciências.

Ao investigar o embate entre esses polos enquanto estratégias de formação, podemos apresentar um esquema interpretativo das mediações que estão em jogo para orientar os significados atribuídos a cada situação encontrada no processo de aprendizagem. Existem as estratégias de formação que compõem a estrutura subjetiva de um comportamento resignado, que analisaremos na primeira parte do texto e que sintetizamos como o complexo do oprimido (Ramalho, 2011). Na segunda parte do texto, apresentaremos a proposta de uma estratégia formativa para enfrentar essa estrutura opressora, analiticamente sintetizada como o circuito dialógico. Neste estudo, apresentamos a pedagogia do oprimido como uma disputa entre estratégias formativas, compostas do complexo do oprimido e do circuito dialógico, enquanto síntese que oferecemos da proposta pedagógica de Paulo Freire.

A análise do complexo do oprimido e do Circuito Dialógico nos mostrará que, em cada momento do processo educativo, mediaçôes pedagógicas (Figari, 2013) são interpostas com o objetivo de regular a comunicação entre os participantes, visando ajustar os ânimos e orientar a atribuição de sentidos em cada nova etapa do processo de aprendizagem. Se enfatizarmos a característica que sintetiza cada uma dessas etapas separadamente, podemos então desenvolver um circuito pedagógico para cada um dos dois processos mencionados. Cada um desses dois circuitos conterá cinco dispositivos pedagógicos, que consideramos centrais, pois destacam a natureza das mediações pedagógicas envolvidas em cada fase. Essa análise nos fornecerá amplos elementos com respeito às mediações pedagógicas orientadas a fazer prevalecer uma opção pela apropriação coletiva de uma situação problemática 
vivida. Desse modo, ao considerarmos o processo de investigação dos temas-geradores como estratégia formativa, buscaremos os dispositivos pedagógicos que desempenham um papel destacado na disputa entre a resignação individual e o exercício da organização coletiva.

Com base nisso, poderemos sintetizar, de acordo com nossa análise, as estratégias de formação em disputa, contrastando o complexo do oprimido com o Circuito Dialógico. Essa analogia, em nossa percepção, nos permitirá destacar o conteúdo particular das mediações pedagógicas envolvidas nos processos de formação mencionados. Ao fim do texto, apresentamos um modelo analítico proposto com o objetivo de promover as experiências populares levadas a cabo pelos movimentos sociais e difundir o pensamento de Paulo Freire.

\section{O COMPLEXO DO OPRIMIDO}

\section{A INVASÃO CULTURAL}

Podemos considerar o que Paulo Freire identifica como a invasão cultural enquanto elemento fundador do complexo oprimido: "[...] a invasão cultural é a penetração que fazem os invasores no contexto cultural dos invadidos, impondo a estes sua visão do mundo, enquanto lhes freiam a criatividade, ao inibirem sua expansão" (Freire, 1987, p. 86).

Trata-se da transmissão, por diversos meios de comunicação e formas institucionais, de algumas diretrizes culturais específicas que são postuladas como corretas, às quais se atribui uma existência natural, como se tivessem aceitação consensual mesmo quando são flagrantemente estranhas à realidade dos diversos grupos que as recebem ${ }^{3}$.

Essa transmissão de informações sobre a cultura opressora, constante e diversificada, configura uma penetração de diretrizes culturais, que imputa valores específicos sobre o que deve ser considerado como bem e mal e critérios sobre o que deve ser considerado certo ou errado. A percepção desses valores sociais é inculcada como se eles fossem algo estático, trans-histórico e originado de causas externas, isto é, alheias à vontade de qualquer indivíduo. Assim, a invasão cultural permite a sobreposição de uma visão de mundo específica sobre as demais existentes: a visão de mundo do opressor sobre a dos oprimidos ${ }^{4}$.

3 Embora as culturas indígena e africana sejam uma parte importante da cultura brasileira (Holanda, 1995), o sociólogo Florestan Fernandes (Oliveira, 2010, p. 121) afirma "[...] que a grande tradição cultural brasileira é de um elitismo cultural fechado, cerrado, numa sociedade na qual se cultivou, sempre, o conhecimento, o livro e até a filosofia da ilustração".

4 Isso é o que Santos (2010) considera como a colonização do saber, levando a um processo de epistemicídio (a morte das outras epistemologias). Quijano (2014) explica que esses critérios de certo e errado constituem um padrão colonial de poder, que ele sintetiza como saber-poder. 
Para tanto, essa transmissão de diretrizes culturais alheias deve se apoiar numa visão focal da realidade, em que seus elementos constitutivos são apresentados apenas parcialmente. Trata-se de uma forma de codificação da totalidade social na qual as contradições da realidade são isoladas em suas partes constitutivas, dificultando-se, com isso, que o sujeito aprendente possa fazer conexões entre elas e associe um problema social vivido por outros com os seus, relacionando-os em suas causas. Como consequência, esse modo "focalista" de existência mantém "ilhadas" as problemáticas dos oprimidos, evitando-se compreender a realidade social como um todo ${ }^{5}$.

A realidade opressora isola suas contradições tornando "[...] impossível apresentar o mundo como problema, mas, pelo contrário, como algo dado, como algo estático, a que os homens devem se ajustar" (Freire, 1987 p. 80). Ao não capturar a totalidade social, essa visão focal apresenta a realidade como algo imutável, diante do qual a única opção é adaptar-se. Dessa forma, a ação cultural antidialógica estabelece uma mitificação das contradições do mundo para que seja impossível apresentá-la como problema. A realidade opressora é mitificada como algo justo (os ricos são os vencedores), natural (uma causalidade externa, assim são as coisas) e imutável (sempre foi assim) 6 .

Por meio dessa manipulação, as elites dominantes vão conformando as populações invadidas aos seus objetivos, moldando seus padrões e seus modos de vida (Freire, 1987, p. 83). Para que esses mitos funcionem, no entanto, a adesão dos oprimidos consiste em aceitar os critérios impostos pelo opressor como algo positivo e a sua série de mitos como verdade.

Em resumo:

A invasão cultural, que serve à conquista e à manutenção da opressão, implica sempre a visão focal da realidade, a percepção desta como estática, a superposição de uma visão do mundo na outra. A "superioridade" do invasor. A "inferioridade" do invadido. A imposição de critérios. (Freire, 1987, p. 91)

\section{A AUTODESVALIA}

O êxito do processo de invasão cultural consiste no reconhecimento, por parte dos invadidos, de sua subalternidade, uma vez que sua cultura se posiciona em um nível inferior, reconhecendo-se, consequentemente, como superiores aos invasores.

5 “A totalidade de uma região é 'pulverizada' em 'comunidades locais', sem que estas comunidades sejam estudadas como totalidade em si, uma vez que, elas mesmas, são parcialidades de outra totalidade (área, sub-região etc.), as quais, por sua vez, são partes integrantes de uma totalidade maior (o país, como parcialidade da totalidade continental)" (Freire, 2005, p. 161).

6 O mito "De que todos são livres para trabalhar onde queiram. Se não lhes agrada o patrão, podem então deixá-lo e procurar outro emprego [...] O mito da propriedade priva$\mathrm{da}$, como fundamento do desenvolvimento da pessoa humana [...] $\mathrm{O}$ mito da operosidade dos opressores e o da preguiça e desonestidade dos oprimidos. O mito da inferioridade 'ontológica' destes e o da superioridade daqueles. Todos esses mitos e mais outros que o leitor poderá acrescentar, cuja introjeção pelas massas populares oprimidas é básica para sua conquista, são levados pela propaganda bem organizada, pelos slogans, cujos veículos são sempre os chamados 'meios de comunicação com a massa'. Como se o depósito desse conteúdo alienante nelas fosse realmente comunicação" (Freire, 1987, p. 79). 
"Como manifestação da conquista, a invasão cultural conduz à inautenticidade do ser invadido. O seu programa responde ao quadro valorativo de seus atores. A seus patrões, a suas finalidades" (Freire, 1987, p. 86).

Uma condição básica ao êxito da invasão cultural é o convencimento por parte dos invadidos de sua inferioridade intrínseca. [...] na medida em que os invadidos vão reconhecendo-se "inferiores" necessariamente irão reconhecendo a "superioridade" dos invasores. Os valores destes passam a ser a pauta dos invadidos [...] estes quererão parecer com aqueles: andar como aqueles, vestir à sua maneira, falar a seu modo. (Freire, 1987, p. 87)

Os enunciados estigmatizantes, amplamente difundidos, sobre a inferioridade dos oprimidos devem convencê-los de sua própria incapacidade, o que ocorre quando passam a escutar de si mesmos que são inferiores. No entanto, isso se configura como um ato de violência uma vez que leva à inautenticidade do ser invadido, freando a sua criatividade ao inibir sua expansão.

A autodesvalia é outra característica do oprimido [...] De tanto ouvirem de si mesmos que são incapazes [...] terminam por se convencer de sua "incapacidade". Falam de si como os que não sabem e do "doutor" como o que sabe e a quem devem escutar. Os critérios do saber que lhes são impostos são os convencionais. (Freire, 1987, p. 28)

Com a sua percepção inibida, o opressor aparece como um ser invulnerável, seja por razões concretas, dado o seu poder que sempre dá um testemunho em contraste com a situação de vulnerabilidade social (a insegurança vital) em que os oprimidos se encontram, seja por razões subjetivas ligadas à sobrevalorização do poder contido nos detentores da hegemonia, uma forma de medo como meio de controle social ${ }^{7}$.

\section{A ADESÃO CULTURAL}

A adesão cultural do oprimido consiste em aceitar os padrões impostos pelo opressor como positivos e, além disso, considerar essa valorização positiva que se faz como uma conclusão própria sua, dando aos mitos opressores o status de verdades. Assim, o oprimido incorpora os padrões culturais alheios como se fossem suas próprias pautas de vida (Freire, 1987, p. 85).

Os invadidos amoldam seus modos de vida, internalizando como sua condição desejante o que, na verdade, está sobredeterminado enquanto conduta prescrita pelos opressores. Todavia, uma vez que a sua finalidade na vida está prescrita pelos opressores, o oprimido carece, ele mesmo, de finalidade (Freire, 1987, p. 51). Quanto mais a maioria da população se adapta às finalidades que the são prescritas pelas minorias dominadoras, mais carecerá de finalidade própria, pois a

7 Os oprimidos "[...] têm uma crença difusa, mágica, na invulnerabilidade do opressor. Em seu poder que sempre dá testemunho" (Freire, 1987, p. 28). 
sua conduta na vida é prescrita pelos opressores. "Toda prescrição é a imposição da opção de uma consciência a outra [...] o comportamento dos oprimidos é um comportamento prescrito. Faz-se a base de pautas estranhas a eles - as pautas dos opressores" (Freire, 1987, p. 18).

A conduta dos oprimidos está prescrita pelos opressores quando se tem como finalidade alcançar o nível de vida do opressor, encarnando-se para essa conquista (que raramente se efetiva) os valores e a conduta das classes ricas. No entanto, o oprimido invadido pela moral e pela condição desejante do opressor atua de maneira contraditória com a sua própria realidade, pois a incorporação dos valores e da conduta das classes ricas como meio para alcançar certo padrão almejado de vida não se mostra coerente com a sua situação existencial concreta. Assim, a adesão cultural conduz à inautenticidade do ser invadido, pois a sua conduta não condiz com a sua realidade. $\mathrm{E}$, nesse processo de adaptação à cultura alheia que recebem as populações invadidas, coloca-se sob ameaça a sua originalidade cultural.

A adesão cultural, então, constitui o oprimido como um ser-para-o-outro (Freire, 1987, p. 20); um ser que existe em função de outro porque esse outro the prescreve como ele deve se comportar. Em cada uma das suas atividades, os oprimidos atuam em benefício dos seus opressores: no âmbito do trabalho, por exemplo, vemos que o fruto do seu labor não lhes pertence e, mesmo que eles dependam disso para viver, só poderão trabalhar na medida em que são explorados em prol do enriquecimento alheio. $\mathrm{E}$ o mesmo podemos dizer que acontece na esfera da educação e da família ${ }^{8}$.

A constituição dual do ser oprimido consiste na ambiguidade da cultura que assimila, fazendo com que parte do seu eu se encontre "aderido" à condição desejante opressora, enquanto outra parte, inegavelmente, está imersa em sua realidade palpável. Assim, o indivíduo permanece dividido, pois a condição de sua própria existência é estabelecida por interesses antagônicos aos seus. A manutenção da dualidade do sujeito oprimido está em relação direta à manutenção de sua adesão à realidade opressora.

Parte de seu $e u$ se encontra na realidade a que se acha aderido, parte fora, na ou nas entidades estranhas, às quais responsabiliza pela força da realidade objetiva, frente à qual nada é possível fazer. Daí que seja este, igualmente, um eu dividido entre o passado e o presente iguais e o futuro sem esperança que, no fundo, não existe. Um $e u$ que não se reconhece sendo, por isto que não pode ter, no que ainda vem, a futuridade que deve construir na união com outros. [...] A própria situação concreta de opressão, ao dualizar o $e u$ do oprimido, ao fazê-lo ambíguo, emocionalmente instável, temeroso da liberdade, facilita a ação divi-

8 "As relações pais-filhos, nos lares, refletem, de modo geral, as condições objetivo-culturais da totalidade de que participam. E, se estas são condições autoritárias, rígidas, dominadoras, penetram nos lares que incrementam o clima da opressão. [...] Esta influência do lar se alonga na experiência da escola. Nela, os educandos cedo descobrem que, como no lar, para conquistar alguma satisfação, têm de adaptar-se aos preceitos verticalmente estabelecidos. E um destes preceitos é o não pensar” (Freire, 1987, p. 87). 
sória do dominador nas mesmas proporções em que dificulta a ação unificadora indispensável à prática libertadora. (Freire, 1987, p. 100)

Para a pedagogia dialógica será indispensável destacar que o ser humano, aderido à natureza e à figura do opressor, encontra-se proibido de estar sendo (Freire, 1987, p. 101). A pedagogia do oprimido tratará de problematizar a sua constituição dual: como existe em função de um outro, ele experimenta uma espécie de "morte em vida",já que a sua vida está sendo proibida de ser vida por ser considerada como uma coisa - sobre a qual incide a dominação.

\section{A HOSPEDAGEM DO OPRESSOR}

Os oprimidos hospedam o opressor quando o assimilam como seu modelo ideal de humanidade. Os opressores, penetrando nos oprimidos, neles se hospedam, fazendo com que estes passem a ter naqueles o seu testemunho de humanidade (Freire, 1987, p. 71). Ao internalizarem as condições desejantes do opressor como suas, os valores dos opressores passam a ser a pauta dos invadidos, que quererão parecer-se com eles, vestir à sua maneira e andar a seu modo: "Há [...] em certos momentos da experiência existencial dos oprimidos uma irresistível atração pelo opressor. Pelos seus padrões de vida. Participar desses padrões constitui uma incontida aspiração. Na sua alienação querem, a todo custo, parecer com o opressor" (Freire, 1987, p. 28).

A dualidade do oprimido compõe-se da ambiguidade da cultura que assimila e culmina na manutenção do seu eu focado em um "outro-exterior". Isso impede que o oprimido adquira consciência de si, isto é, consciência de sua condição existencial particular e da existência social de sua classe, enquanto percepção da situação — nada única - de opressão em que se encontra, a qual é correlata a variados contextos de outros oprimidos.

O foco de suas aspirações está posto em alcançar um padrão de vida alheio, encontrado em uma realidade longínqua, com o que ele evita encarar as condições interiores do território que habita em relação com seus pares (Ramalho, 2011). Assim, o oprimido tende a elaborar apenas soluções individuais para os seus problemas sociais, pois tem constringida a possibilidade de pensar outras formas para apropriar-se da sua situação. Caso projete a visão de um ser humano distinto, novo, melhor, esta será uma visão individualista, tal como lhe pauta a cultura opressora ${ }^{9}$.

Aderidos à cultura dos dominadores, a única opção que lhes parece plausível consiste em integrar-se à estrutura opressora; em buscar fazer parte dela ou gravitar ao seu redor. Desse modo, eles veem a adaptação constante como a única solução factivel. "A estrutura de seu pensar se encontra condicionada pela contradição vivida na situação concreta, existencial, em que se 'formam”' (Freire, 1987, p. 17).

9 "A sua visão do homem novo é uma visão individualista. A sua aderência ao opressor não lhes possibilita a consciência de si como pessoa, nem de consciência de classe oprimida" (Freire, 1987, p. 18). 
Como os oprimidos têm no opressor o seu testemunho de humanidade, normalmente sua conduta reproduz a opressão da qual são testemunha, até porque não aprenderam nada mais. Por terem no opressor o seu exemplo ideal de ser humano, os oprimidos reproduzem a opressão que vivenciam, pois todo o seu ser se desenvolve no jogo dessas contradições, dessa ambiguidade. "O seu ideal é, realmente, ser homens, mas, para eles, ser homens, na contradição em que sempre estiveram e cuja superação não lhes está clara, é ser opressor. Estes são o seu testemunho de humanidade" (Freire, 1987, p. 17).

\section{O MEDO DA LIBERDADE}

$\mathrm{Na}$ medida em que os oprimidos hospedam o opressor como o seu "senhor", eles passam a temer a sua própria liberdade. "Os oprimidos, que introjetam a sombra dos opressores e seguem suas pautas, temem a liberdade, na medida em que esta, implicando a expulsão desta sombra, exigiria deles que preenchessem o vazio deixado pela expulsão com outro conteúdo - o de sua autonomia" (Freire, 1987, p. 18). Como o oprimido tem no opressor o seu exemplo ideal de humanidade, a princípio não sabe por qual outro conteúdo poderia substituir as pautas culturais alheias que lhe são impostas, pois estas lhe são imputadas como algo natural e até mesmo desejável. Em sua ambiguidade, ele teme cair numa espécie de vazio se descartar a tão bem estruturada visão de mundo imposta pelos opressores. O medo de ver-se como que se precipitando a um abismo equivale, então, ao medo da liberdade (Freire, 1987, p. 18).

A realidade opressora possui essa característica de funcionar como uma força de imersão das consciências ao constituir-se como uma espécie de mecanismo de absorção dos que nela se encontram (Freire, 1987, p. 21). Imersos na engrenagem da estrutura opressora, os oprimidos temerão a liberdade enquanto não assumirem o risco de enfrentar a sua situação de opressão (Ramalho, 2011). Em vez disso, eles normalmente apelam para explicações mágicas ou para uma visão fatalista da realidade (cheia de poderes imutáveis), às quais transferem a responsabilidade de sua situação.

A emersão das consciências lhes exigirá reconhecer sua ambiguidade e assumir o risco de enfrentá-la - no sentido do reconhecimento crítico da ordem opressora, de sua situação não autêntica de "hospedeiros" dessa ordem — para, com base na crítica à hegemonia vigente, não verem mais a sua realidade como um "mundo fechado”, mas como um limite imposto externamente, logo transformável.

O grande problema está em como poderão os oprimidos, que "hospedam" o opressor em si, participar da elaboração, como seres duplos, inautênticos, da pedagogia de sua libertação. Somente na medida em que se descubram "hospedeiros" do opressor poderão contribuir para o partejamento de sua pedagogia libertadora. (Freire, 1987, p. 17)

Uma vez que a visão de mundo do oprimido está estruturada por toda uma série de padrões estranhos à sua realidade, sua autonomia (liberdade) só é factível se ele aceitar o desafio de reconstruir a sua ordem cognitiva do mundo e assumir a responsabilidade de fazer emergir uma estrutura nova, preenchida por um conteúdo 
próprio. Os oprimidos devem desenvolver sua compreensão da realidade enquanto processo, isto é, o entendimento de que a realidade se forma nas relações que o ser humano estabelece com ela. Primeiramente se transforma a percepção do mundo pela dicotomização entre a consciência oprimida e a opressora. Depois se procede a expulsar os mitos da estrutura opressora, os quais se preservam apenas como espectros míticos na nova estrutura subjetiva, preenchida com um outro conteúdo próprio, o de sua autenticidade.

Em contraposição ao Complexo do oprimido exposto, apresentaremos agora o Circuito dialógico como a síntese que oferecemos da proposta pedagógica de Paulo Freire (Ramalho, 2011). A emersão da consciência das populações oprimidas dá-se pelo processo grupal desenvolvido por meio da ação pedagógica enquanto processo formativo que transita da "adesão cultural" predominante à formação de um "inédito-viável", que emerge como uma proposta nova, entendida como viável para o grupo participante do processo de aprendizagem.

\section{O CIRCUITO DIALÓGICO}

\section{O CONTEÚDO PROGRAMÁTICO}

No esquema proposto, a ação pedagógica começa com o diálogo sobre o conteúdo programático a ser ensinado. A organização do conteúdo programático, em uma área determinada de estudo, tem como premissa a abordagem dos temas que, no diálogo, aparecem como significativos para os participantes do processo ${ }^{10}$.

Em todo caso, é essencial que o movimento parta das relações que os participantes estabelecem com a sua realidade local e imediata — como diz Paulo Freire, de uma relação homem-mundo baseada em seu aqui e em seu agora ${ }^{11}$. Sendo assim, não se trata de abordar uma temática em geral, como o desemprego em um país ou a desigualdade em todo o mundo, mas de propor uma discussão baseada nas contradições estruturais específicas presentes na situação existencial concreta das pessoas. Isso porque é da discussão entre os seres humanos sobre seu contexto tangível, sobre o que estão fazendo e como estão agindo, que surgem os anseios, dúvidas, angústias e desejos vividos, cuja expressão conforma a matéria-prima da investigação sobre o universo temático compartido pelo grupo.

Dessa forma, esta proposta pedagógica implica uma reflexão sobre o mundo para trazer à tona os temas significativos nele implícitos e, com isso, delimitar um universo temático que reflita o conjunto de aspirações comuns aos participantes. Em geral, a organização do conteúdo programático consiste em uma investigação sobre o universo temático do grupo com o intuito de elaborar uma síntese

10 Isso não significa que o educador esteja privado de buscar informações prévias para adquirir certa familiaridade com a situação em que se encontrará: "Delimitada a área em que se vai trabalhar, conhecida através de fontes secundárias, começam os investigadores a primeira etapa da investigação" (Freire, 1987, p. 59).

11 "[...] o movimento parte das relações homem-mundo. Daí que este ponto de partida esteja sempre nos homens no seu aqui e no seu agora [...]" (Freire, 1987, p. 42). 
cultural a respeito da sua visão de mundo. A visão de mundo das pessoas reflete sua situação existencial e manifesta-se nas diversas formas de ação que os seres humanos adotam ou estão dispostos a adotar. No entanto, devemos enfatizar que a investigação do conteúdo programático tem por objeto não os participantes do processo em si, mas o pensamento-linguagem que o grupo aprendente utiliza para referir-se a suas experiências e os diferentes níveis de percepção sobre a realidade existentes entre eles.

"Será a partir da situação presente, existencial, concreta, refletindo o conjunto de aspirações do povo, que poderemos organizar o conteúdo programático" (Freire, 1987, p. 49).

Nosso papel não é falar ao povo sobre a nossa visão do mundo, ou tentar impô-la a eles, mas dialogar com eles sobre a sua e a nossa. Temos de estar convencidos de que sua visão do mundo, que se manifesta nas várias formas de sua ação, reflete sua situação no mundo, em que se constitui. (Freire, 1987, p. 49)

O que se pretende investigar, realmente, não são os próprios homens, como se fossem peças anatômicas, mas o seu pensamento-linguagem referido à realidade, a sua visão de mundo, em se encontram envolvidos os seus temas-geradores. (Freire, 1987, p. 50)

\section{OS TEMAS-GERADORES}

A tarefa do educador dialógico não é "reapresentar", desde outro ponto de vista, o universo temático captado, no sentido de dissertar sobre algum ponto do universo temático para esclarecer questões adjacentes ao conteúdo fixado de forma disciplinar, mas sim "representar" o universo temático recebido como problema. Trata-se de trabalhar em equipe o universo temático recolhido na investigação para devolvê-lo como problema às pessoas de quem se o recebeu ${ }^{12}$.

Com base nesse universo temático elaborado entre todos, vão se esclarecendo certos temas centrais do debate. A delimitação dos temas-geradores a serem desenvolvidos considera aqueles assuntos que possuem uma interface entre o conhecimento científico e demais saberes - aqueles que mais aparecem em sua potencialidade de desdobramento enquanto desafio que exige resposta. Resposta que tem seu potencial de desdobramento no caráter desafiante que se atribui a ela e sobre a qual se sente ser necessário incidir a sua ação, em uma situação tangível e em um contexto determinado.

À medida que os participantes do processo, refletindo simultaneamente sobre si e sobre o mundo, vão estabelecendo correlações entre os diferentes aspectos da realidade para irem desdobrando as estreitezas das situações apreendidas, eles

12 "A tarefa do educador dialógico é, trabalhando em equipe interdisciplinar este universo temático, recolhido na investigação, devolvê-lo, como problema, não como dissertação, aos homens de quem recebeu" (Freire, 1987, p. 59). 
passam a captar a realidade em suas implicações mais profundas, ampliando o seu campo de percepção. Os indivíduos expandem sua percepção ao realizarem uma análise das dimensões parciais que os impactam, apreendendo temas nelas implícitos ou a elas referidos e observando a interação entre os elementos da realidade que compõem uma totalidade.

A investigação sobre os temas-geradores implica um ato constante de desvelamento da realidade, no sentido de erigir um plano de totalidade pela organização de seus elementos constitutivos. Trata-se de adquirir a capacidade de cindir um tema em seus núcleos fundamentais, que são suas parcialidades, para mais adiante poder voltar a adentrar-se na totalidade, conhecendo-a melhor (Freire, 1987, p. 67). Ao ser capaz de mover-se do geral ao particular (e vice-versa), compreende-se em que medida um aspecto regional pode conter temas que são de caráter universal, no sentido de pertencerem a uma unidade epocal mais ampla.

[...] faltando aos homens uma compreensão crítica da totalidade em que estão, captando-a em pedaços nos quais não reconhecem a interação constituinte da mesma totalidade, não podem conhecê-la. E não o podem porque, para conhecê-la, seria necessário partir do ponto inverso. Isto é, lhes seria indispensável ter antes a visão totalizada do contexto para, em seguida, separarem ou isolarem os elementos ou as parcialidades do contexto, através de cuja cisão voltariam com mais claridade à totalidade analisada. (Freire, 1987, p. 55)

Os temas-geradores podem ser localizados em círculos concêntricos, que partem do mais geral ao mais particular. Temas de caráter universal, contidos em uma unidade epocal mais ampla, que abarca toda uma gama de unidades e subunidades, continentais, regionais, nacionais etc. [...]. (Freire, 1987, p. 54)

Nesse momento em que os oprimidos vão desvelando o mundo da opressão, devemos ter em mente que essa mudança de percepção do mundo opressor por parte dos oprimidos nos coloca diante do problema da consciência oprimida e da consciência opressora; isto é, da dualidade dos oprimidos. "E é como seres duais, contraditórios, divididos, que temos de encará-los" (Freire, 1987, p. 23). A compreensão da totalidade move-se no sentido de sedimentar a percepção a respeito da dicotomia existente entre as visões de mundo dos opressores e dos oprimidos. Isso significa: ganhar uma consciência crítica da opressão, desenvolvendo-a por meio da compreensão crítica da dicotomia entre consciência opressora e oprimida.

Quanto mais os participantes desvelam a realidade objetiva da opressão, mais se inserem criticamente nela na medida em que começam a questionar a ordem opressora. Uma vez que eles desvelam o mundo da opressão e percebem os mitos que o alimentam, a exigência de influir na situação concreta de opressão está, então, em seu estágio de conformação.

\section{A SITUAÇÃO-LIMITE}

Quando o diálogo se aprofunda e atinge um certo ponto de pico, nos quais a discussão fica tensa, aparecem, então, as situaçôes-limite. Uma situação-limite 
mostra-se na abordagem de temas considerados como tabus, sobre os quais não se deve ou é melhor não falar, e que são colocados como construções simbólicas fixas na rede cognitiva das pessoas. São situações vistas como insuperáveis, assuntos tratados como determinações impossíveis de se mudar, aos quais se atribui uma existência de caráter natural (sempre foi assim) e de aceitação universal (como se fossem transmitidos por possuírem uma aceitação consensual) ${ }^{13}$.

O desenvolvimento da situação-limite consiste em questionar esses preceitos percebidos como naturais e universais. Ao se desvendar como eles são construídos, eles podem ser mostrados enquanto mitos que encobrem a realidade, restringindo a disposição para perceber e agir.

[...] os temas (da vida) se encontram encobertos pelas "situações-limites", que se apresentam aos homens como se fossem determinantes históricas, esmagadores, em face das quais não lhes cabe outra alternativa senão adaptar-se. (Freire, 1987, p. 53)

"Em geral, uma consciência dominada, que ainda não percebeu uma situação-limite em sua totalidade, apreende apenas seu epifenômeno e transfere para este último a força inibidora, que é propriedade da situação-limite"(Freire, 1987, p. 54).

A percepção da dicotomia entre opressor e oprimido deve destacar a contradição na qual a cultura apresentada pelo opressor não corresponde à realidade dos oprimidos. O tratamento da situação-limite transita na direção de expressar a ambivalência existente entre a pauta cultural transmitida pelos opressores e a situação existencial dos oprimidos, tal como a existência de critérios antagônicos na determinação dos preceitos disseminados como o que é certo e o que é verdadeiro.

Munidos com um panorama holístico sobre seu contexto específico, os oprimidos podem então destacar a dicotomia existente entre a consciência oprimida e a opressora, de modo que as pautas culturais da estrutura invasora, na consciência oprimida, possam ser explicitamente reveladas como um fenômeno mítico - e, portanto, não passível de realização. A compreensão de que a realidade é constituída das relações que os seres humanos estabelecem com ela remove o véu que a encobre como algo naturalmente dado, pois a definição do que equivale ao certo e ao errado se fundamenta em critérios socialmente construídos, os quais são antagônicos à situação em que se encontram os oprimidos.

13 Freire (1987,p. 54) menciona o exemplo do subdesenvolvimento de um país, por exemplo, o Brasil, que é encarado com naturalidade, como uma espécie de "desígnio do destino". Entretanto, ele não é casual se o encaramos como consequência da estrutura da dependência econômica. Nessa situação-limite se igualam todas as medidas tomadas no sentido de trazer algum desenvolvimento (ainda que dependente) como sendo o equivalente à modernização, ainda que os benefícios dessa "modernidade" estejam induzidos em prol dos países centrais do capitalismo mundial. "Por tudo isto, é preciso não confundir desenvolvimento com modernização. Esta, sempre realizada induzidamente, ainda que alcance certas faixas da "sociedade satélite", no fundo interessa à sociedade metropolitana” (Freire, 1987, p. 92). 
Desse modo, aquela situação que antes parecia imutável e de origem independente, ao mostrar-se em sua ambivalência, tensiona e emerge como uma contradição que já não pode persistir, ou seja, uma situação da vida que mostra a coexistência de padrões antagônicos e que, portanto, requer uma solução. Nesse sentido, a tensão conforma parte necessária do processo pedagógico proposto por Paulo Freire, uma vez que é colocada como mediação pedagógica consciente no tratamento da situação-limite por expressar a convivência de critérios antagônicos - entre os quais, então, os participantes do processo devem tomar uma posição.

Se se faz indispensável aos oprimidos, para a luta por sua libertação, que a realidade concreta de opressão já não seja para eles uma espécie de "mundo fechado" (em que se gera o seu medo de liberdade) do qual não pudessem sair, mas uma situação que apenas os limita e que eles podem transformar, é fundamental, então, que, ao reconhecerem o limite que a realidade opressora lhes impõe, tenham, neste conhecimento, o motor de sua ação libertadora. (Freire, 1987, p. 19)

A elucidação da ambiguidade contida na assimilação de uma cultura fundada em interesses antagônicos aos seus permite que os indivíduos se descubram como hospedeiros do opressor e notem que, como seres duais, não estão sendo capazes de ser (Freire, 1987, p. 49). Quando percebem a impossibilidade de sua realização na vida mantendo sua conivência com o regime opressor, destaca-se a necessidade de superar a contradição em que se encontram como forma de se tornarem seres-para-si.

O processo de elaboração de uma totalidade social amplia a percepção da pessoa sobre a dicotomia existente entre as visões de mundo do opressor e do oprimido, para que ela possa alcançar um olhar mais introspectivo, voltado para si e suas aspirações na vida. Tal dicotomia também pode ser traduzida como a oposição entre o ser-para-si e o ser-para-o-outro. Reconhecendo que seu comportamento está pautado por interesses antagônicos aos seus, o indivíduo passa a se perguntar sobre como estabelecer critérios próprios para assumir uma conduta coerente com a situação em que se encontra no mundo. Por meio desse processo dialógico, percebe que: "Sua solução não está em integrar-se, em incorporar-se a esta estrutura que os oprime, mas em transformá-la para que possam fazer-se seres para si” (Freire, 1987, p. 35).

\section{O PERCEBIDO-DESTACADO ${ }^{14}$}

A problematização de uma situação-limite deve destacar a percepção dos impedimentos que discutimos acima, das coisas que são consideradas como tabus, enquanto referências exemplares de problemas no mundo a ser transformados: de injustiça, de desigualdade. Uma vez que esses tabus são entendidos como tais

14 Ana Maria Araújo Freire (2014) considera especialmente significativo estudar de forma mais profunda o trânsito da situação-limite para o percebido-destacado como uma forma de entender a construção do inédito-viável. Isso, em sua opinião, é pouco explorado, dada a importância que esse conceito tem na compreensão da obra de Paulo Freire. 
— restrições, limitações —, os oprimidos começam a vê-los como obstáculos às suas aspirações, transformando-os em percebidos-destacados. Esse destaque, que se realiza na Educação Dialógica, enfatiza o caráter problemático da situação em que os oprimidos se encontram, e então, em vez de uma situação-limite, insuperável, adquire-se a percepção de um desafio a ser superado.

"O que antes existia como objetividade, mas não era percebido em suas implicações mais profundas e, às vezes, nem sequer era percebido, se destaca e assume o caráter de problemas e, portanto, desafios" (Freire, 1987, p. 41).

Se as situações-limite tratam de estruturas mentais e comportamentais que aparecem como fixas e eternas, agora, como percebidos-destacados (Freire, 2014), elas emergem como o ponto de referência de um contexto desafiador que precisa ser enfrentado. A situação, inicialmente enfrentada como algo dado, ao ser vista em suas diversas conexões e implicações mais profundas adota o caráter de um problema a ser superado. No momento em que assumimos uma situação como problemática, passamos também a questionar-nos sobre a necessidade de resolvê-la, sobre como alcançar uma solução para essa posição dilemática.

No processo de investigação, quando os indivíduos problematizam sua conduta no mundo, eles reconhecem suas próprias características e propriedades singulares. Quanto mais se problematizam, mais vão se reconhecendo, identificando-se nele. E, à medida que percebem que estão se reconhecendo no processo de problematização, erige-se um movimento no qual o indivíduo se engaja, pois a sua compreensão resultante torna-se crescentemente crítica, com base na conexão que ele faz de sua situação problemática com outras relativas. Daí a relação entre reconhecimento e compromisso na pedagogia do oprimido:

Quanto mais se problematizam os educandos, como seres no mundo e com o mundo, tanto mais se sentirão desafiados. Tão mais desafiados, quanto mais obrigados a responder ao desafio. Desafiados, compreendem o desafio na própria ação de captá-lo. Mas, precisamente porque captam o desafio como um problema em suas conexões com outros, num plano de totalidade e não como algo petrificado, a compreensão resultante tende a tornar-se crescentemente crítica, por isto, cada vez mais desalienada. Através dela, que provoca novas compreensões de novos desafios, que vão surgindo no processo de resposta, se vão reconhecendo, mais e mais, como compromisso. Assim é que se dá o reconhecimento que engaja. (Freire, 1987, p. 40)

O reconhecimento crítico da "razão" de sua situação impõe ao indivíduo a necessidade de superar essa situação contraditória, na medida em que isso lhe aparece como condição para alcançar suas aspirações. Não tendo mais o seu comportamento prescrito pela adesão às pautas culturais da estrutura opressora, organiza-se, paulatinamente, um sistema de disposições para perceber e atuar em busca daquilo que lhe aparece como condição para o ser-mais. Isto é, conforma-se uma disponibilidade para atuar no sentido de incidir sobre a estrutura opressora na construção das suas possibilidades de ser mais, de erigir-se como ser autêntico, um ser-para-si. 
Ao tomar consciência da totalidade social em que estão inseridos, os indivíduos, até então imersos em sua realidade, apenas com a pura sensibilidade de suas necessidades, emergem dela ao adquirirem a razão de suas necessidades, atribuindo um sentido à realização de suas aspirações no mundo. Quando os oprimidos descobrem o opressor, começam a acreditar em si mesmos porque reconhecem os contornos dos aspectos que conformam a hegemonia, percebendo que sua capacidade de agência sobre a realidade pode ser limitada, mas não é inexistente.

Os indivíduos reconhecem-se nos problemas que desenvolvem nesse processo de investigação (que nascido do tema-gerador alcançou uma situação-limite, para, então, tornar-se um percebido-destacado, a transubstanciar-se, agora, em inédito-viável) e passam a aceitar sua responsabilidade perante a sua própria situação: “[...] a concepção problematizadora, que, não aceitando um presente 'bem-comportado', não aceita igualmente um futuro pré-dado, enraizando-se no presente dinâmico, se faz revolucionária" (Freire, 1987, p. 42).

O tratamento do percebido-destacado consiste no desenvolvimento dessa confrontação, colocando para os seres humanos como algo próprio seu sua condição de estar em relação de enfrentamento com a realidade na qual se dá historicamente a razão de sua situação social. A incorporação dos antagonismos sociais não mais como um limite (um teto social), mas como problema a solucionar, erige a noção de existir uma fronteira a ser superada. Os "limites" aparecem, agora, como fronteiras que separam duas coisas: a verdade do opressor e a autonomia do oprimido. A realidade aparece como essa situação fronteiriça, encarada, então, como um limite à autonomia, à realização da pessoa em sua vida. Em vez de uma barreira insuperável, esse limite passa a ser interpretado como fronteira entre o ser-para-si e o ser-para-o-outro, entre o ser-mais e o ser quase-coisa, logo, entre o ser e o nada - habilitando a inversão do medo em liberdade que abordamos na primeira parte do texto.

No momento em que os oprimidos percebem as situações-limite não mais como uma "[...] fronteira entre ser e nada, mas como uma fronteira entre ser e ser mais [...]" (Freire, 1987, p. 51), tornam-se cada vez mais críticos em suas ações, ligadas a essa percepção. Percepção esta em que está implícito o inédito-viável, a ser então definido - e uma vez definida a possibilidade de mudança, de novo, sua concretização se dirigirá as ações dos participantes do processo formativo.

\section{O INÉDITO-VIÁVEL}

Quando o desafio erigido do processo formativo é percebido como algo insustentável, sobre o qual se faz impostergável atuar, o percebido-destacado adquire condições de transformar-se em inédito-viável. A transubstanciação do percebido-destacado em inédito-viável exige que esses impedimentos destacados já apareçam enquanto contradição que não pode seguir existindo (tal como é, sem que se faça nada a respeito). "A tendência, então, do educador-educando como dos educando-educadores é estabelecerem uma forma autêntica de pensar e atuar. Pensar-se a si mesmos e ao mundo, simultaneamente, sem dicotomizar este pensar da ação" (Freire, 1987, p. 41).

Essa não separação entre palavra e ação a que se refere Freire consiste no resultado do processo em que ocorre a emersão das consciências, uma vez que a 
recodificação da totalidade social foi realizada. No desenvolvimento da investigação sobre o tema-gerador, chegamos a um ponto em que parece existir certa desorganização da realidade social, fruto do processo de cindir o tema em seus núcleos fundamentais, que são suas parcialidades, para mais adiante voltar a adentrar-se na totalidade, conhecendo-a melhor. A totalidade social, inicialmente codificada como estrutura rígida, natural e universal, é então descodificada pela compreensão de suas diversas dimensões constitutivas (Freire, 1987, p. 67).

Essa cisão da totalidade codificada permite a reorganização de seus elementos constitutivos para que as pessoas reconheçam a interação constituinte das diversas dimensões da totalidade em que estão inseridas. A totalidade é dividida — descodificada - para ser, então, recodificada, conformando-se, com isso, uma retotalização - recodificação - da totalidade cindida. Consequentemente, essa desorganização inicial da realidade social, que, em sua persistência, necessita ser redefinida faz com que a realidade social apareça, agora, como passível de ser reorganizada. A essa reorganização se deve atribuir o sentido de se estar transpassando uma situação fronteiriça, encarada como um limite à autonomia, à realização do indivíduo. Nesse momento de recodificação, está-se conformando a possibilidade da novidade, de uma proposição inédita, que a princípio parecia inviável.

$\mathrm{O}$ processo tem seu desenlace quando a negação do existente se converte em proposta: a de se criar algo novo, inédito até então para o grupo. Essa busca pelo novo "[...] implica o reconhecimento crítico da 'razão' desta situação, para que, através de uma ação transformadora que incida sobre ela, se instaure uma outra, que possibilite aquela busca do ser mais"(Freire, 1987, p. 18). Num primeiro momento, o enfrentamento com a cultura da dominação ocorre por meio de uma mudança na percepção sobre o mundo opressor por parte dos oprimidos, à medida que eles vão desvelando o mundo da opressão e se comprometendo com a sua transformação. Neste segundo momento, em que estamos, dá-se a expulsão dos mitos criados pela estrutura opressora, a preservarem-se, na nova estrutura, apenas como espectros míticos da realidade, agora preenchida com outro conteúdo, próprio, autêntico.

O Circuito Dialógico destaca o caráter processual da pedagogia do oprimido, pois é do processo mesmo de se ir transformando a realidade opressora que se habilita a superação desta e o surgimento de seres humanos novos - não mais opressores, não mais oprimidos, mas libertando-se, em processo, mutuamente. Um processo de libertação permanente baseado em "[...] trabalhos educativos, que devem ser realizados com os oprimidos, no processo de sua organização" (Freire, 1987, p. 23).

A pedagogia do oprimido é a práxis da organização coletiva na busca pela restauração da intersubjetividade entre os participantes do processo, fazendo dos oprimidos o exemplo para si mesmos na luta por sua emancipação. A investigação dos temas-geradores, que configura o Circuito Dialógico, institui um processo de comunicação que orienta a ação e a reflexão dos participantes sobre o seu mundo a fim de se criar uma nova estrutura no próprio processo de incidir sobre ela. Nesse sentido, podemos dizer que o diálogo fenomeniza a intersubjetividade humana (Macedo, 2005, p. 8).

Esse processo consiste na emergência da novidade, entre os oprimidos, pela superação da contradição opressores-oprimidos. Com a recodificação da totalida- 
de, a superação do medo rumo à liberdade é possível. O tratamento adequado da contradição opressores-oprimidos, no desenvolvimento do processo grupal, é o que possibilita que se preencha o vazio deixado pela negação da estrutura opressora.

O Circuito Dialógico culmina na emergência de uma solução inédita, porém crivel para os participantes do grupo, estabelecendo uma espécie de tríade entre problematização-desafio-compromisso a atuar (Ramalho, 2011). Sobre os mitos individualizantes da visão de mundo opressora, a teoria da ação dialógica destaca suas características: cooperação, unidade, organização e síntese cultural (Freire, 1987, p. 96).

\section{CONCLUSÕES}

No estudo aqui apresentado, examinamos a pedagogia do oprimido como o embate entre as estratégias de formação do opressor e do oprimido, fundada na oposição entre imersão/emersão das consciências. Desse ponto de vista, apresentamos a teoria de Paulo Freire sobre a pedagogia do oprimido dividida em duas partes: o complexo do oprimido e o circuito dialógico. Primeiramente, especificamos os componentes centrais do complexo do oprimido, que resultam no medo da liberdade, enquanto conduta de resistência ao novo. Em seguida, mostramos o Circuito Dialógico como um processamento de mediações que culmina na emergência de uma solução inédita, porém tida como viável para o grupo em formação - o inédito- viável. Dessa forma, podemos considerar que o complexo do oprimido encontra sua superação no Circuito Dialógico, enquanto síntese que oferecemos da proposta pedagógica de Paulo Freire.

Nosso estudo destaca que a dualidade do sujeito oprimido é composta da ambiguidade da cultura que ele assimila, fundada em interesses antagônicos aos seus e a qual faz com que ele esteja focado em um outro-exterior. Enquanto hospedeiros da ordem opressora, os oprimidos não considerarão plausível comportar-se de modo diferente daquilo que consideram como o ideal. Assim, os oprimidos não possuem outra forma de conduta que não seja reproduzir a opressão da qual são testemunhas.

Como vimos, o Circuito Dialógico começa com a definição do conteúdo programático a ser ensinado. Dessa forma, a proposta de Freire incorpora um $r a-$ dicalismo metodológico com relação ao ponto de partida da ação pedagógica, contido no fato de que o conteúdo a ser ensinado não pode estar previamente determinado nem pelo educador nem pelo currículo.

Também vimos a centralidade que assume a mediatização do mundo na pedagogia do oprimido. A mediação do mundo, da qual Freire fala, não consiste em usar aspectos da realidade como um gancho, ou seja, como mero recurso didático para que o conteúdo da disciplina se torne mais interessante, aproximando-o da realidade do aluno. A intenção é elaborar o universo temático compartilhado pelo grupo, o qual se captura pela apreensão do pensamento-linguagem que os participantes utilizam para expressar suas experiências e sem a qual a ação pedagógica está comprometida, na perspectiva freiriana. Por conseguinte, o objeto da investigação dos temas-geradores não são os próprios estudantes, mas sim o pensamento-linguagem que os participantes do grupo usam para se referir à sua realidade, às suas experiências 
de vida no mundo. Neste sentido é que a diferenciação entre educador e educando se esvai, pois o pensamento-linguagem referido ao universo temático comum dos participantes do processo, que trata de captar, inclui também o sujeito responsável pelo fazer docente.

De nossa perspectiva, examinamos o processo de conformação grupal que institui a ação da pedagogia dialógica. Mostramos que, entre cada um dos momentos do processo, interpõem-se mediações pedagógicas com o propósito de regular a comunicação entre os participantes, para ajustar os ânimos entre opiniões desencontradas ou opostas e orientar a formulação dos sentidos outorgados mediante cada novo desafio que surge nesse processo. Ao acentuarmos a característica que sintetiza cada uma dessas etapas separadamente, pudemos discernir dois circuitos pedagógicos opostos - o complexo do oprimido e o circuito dialógico. Cada um está composto de cinco dispositivos pedagógicos centrais, os quais, em nossa percepção, permitem-nos destacar o conteúdo particular e o desenvolvimento esperado das mediações pedagógicas envolvidas no processo de formação.

Com base nisso, podemos, de acordo com a nossa análise, sintetizar as estratégias de formação em disputa ao contrastar o complexo do oprimido com o Circuito Dialógico. Apresentamos nosso esquema analítico, pautado por esse paralelo delineado. Dessa forma, estruturamos um modelo analítico para visualizar o método Freire, proposto conforme o Quadro 1.

Quadro 1-Sistematização da pedagogia do oprimido.

\begin{tabular}{|l|c|c|}
\hline & O complexo do oprimido & 0 circuito dialógico \\
\hline 1. & Invasão cultural & Conteúdo programático \\
\hline 2. & Autodesvalia & Tema-gerador \\
\hline 3. & Adesão cultural & Situação-limite \\
\hline 4. & Hospedagem do opressor & Percebido-destacado \\
\hline 5. & Medo da liberdade & Inédito-viável \\
\hline
\end{tabular}

Elaboração do autor.

Nessa ótica, vemos a pedagogia do oprimido como uma disputa entre estratégias de formação do opressor e do oprimido, que se joga entre a (auto)resignação individual e o (auto)exercitamento da organização coletiva. Seu resultado pode ser tanto o autodisciplinamento perante a adesão cultural quanto a emergência de uma (auto)didática do exercitamento grupal, dirigida à apropriação de uma situação problemática vivida.

A apropriação coletiva de uma situação problemática vivida constitui o inédito-viável. A elaboração de um projeto com base na percepção generalizada sobre uma fronteira que necessita ser traspassada, habilita una atitude organizativa, encarnada pelos participantes do grupo como o seu horizonte de êxito plausível. Ao buscar materializar suas reivindicações, os membros do grupo conformam mecanismos de reciprocidade que fazem prevalecer a percepção de que a solução para o problema delineado não se encontra em elementos externos, mas sim no grupo, em 
seu processo de auto-organização. Nessa abordagem, podemos pensar a pedagogia do oprimido como o processo de ruptura com o habitus (Bourdieu, 2007) até então hegemônico, na medida em que esse circuito de mediações culmina na elaboração de um novo sistema de disposiçóes para pensar e atuar.

Quando olhamos para o processamento pedagógico interno do grupo como um elemento central de entendimento, podemos ressaltar que, se esse circuito for interrompido em algum ponto das mediações delineadas, a possibilidade de apropriação dos indivíduos sobre a sua situação estará ameaçada, caso essa didática do exercício coletivo se debilite. O esquema grupal pode estancar-se entre as posições dilemáticas a se enfrentar no desenvolvimento das tarefas do grupo. Por exemplo, no caso de alguns se recusarem a assumir funções atribuídas pelo grupo, preferindo delegá-las a terceiros em vez de consolidarem um mecanismo interno de autorregulação (Calloway, 2016). A persistência de uma subjetividade oprimida entre os participantes indica uma ressignificação apenas parcial da visão de mundo opressora - um despejo ambíguo do opressor como ideal de vida, por exemplo, quando formas de integração à estrutura opressora permanecem como o objetivo almejado, ainda que por vezes de forma velada.

Então, entre cada etapa do processo, são distintos os níveis de percepção entre os participantes do grupo sobre o sentido atribuído à ação que eles levam a cabo, mesmo que haja um objetivo consensual entre eles (resolver o desafio destacado). Como os significados atribuídos a cada momento do processo podem ser diferentes entre os participantes do grupo, a existência de diferentes níveis de percepção sobre a realidade pode derivar-se em diferentes formas de visualizar uma solução para a problemática destacada: uns podem resignar-se a uma solução individual, enquanto outros tratam de enfrentar coletivamente a realidade desafiadora.

Os diferentes graus de assimilação existentes entre os participantes, sobre cada fase desse circuito, podem se traduzir em um despejo apenas parcial do opressor hospedado se virmos as pautas de conduta daquelas pessoas nas quais persiste uma subjetividade calcada pela estrutura opressora. Entre os membros do grupo, pode-se verificar uma continua tensão entre resignação individual e apropriação coletiva. Isso é fruto de uma complexa equação entre a ruptura da normatividade social estabelecida e a reprodução das identidades prévias, o que impacta sobre a forma com que se consolida a conformação do grupo.

A forma específica pela qual cada grupo atravessa o seu processo de investigação dos temas-geradores condiciona a transubstanciação da identidade anterior em outra auto-organizada. Mesmo depois de conformado o inédito-viável, a apropriação da situação vivida não significa, necessariamente, a constituição de um grupo plenamente consciente de suas atribuições na gestão de sua situação identificada como problemática. De um ponto de vista genérico, a conformação grupal encontra-se em uma situação de permanente disputa entre consolidação e reversibilidade, pois as estratégias formativas da estrutura opressora não cessam a sua incidência com o estabelecimento do inédito-viável.

A conformação grupal, que compõe a pedagogia do oprimido, implica um processo contínuo, pois há sempre o risco latente de regresso no reestabelecimento da condição prévia caso a construção da situação de novidade, do inédito-viável, não seja retomada permanentemente. E, mesmo após o alcance do inédito-viável, podemos 
dizer que se inicia um novo processo de aprendizagem, no qual estará em jogo, por exemplo, o caráter da conformação grupal alcançada: o seu nível de horizontalidade interna e suas formas de lidar com as contradições externas, advindas da estrutura opressora, que sempre se fará presente enquanto for hegemônica sobre a totalidade social. A disputa entre estratégias formativas envolve, agora, definir qual percepção imperará sobre o caráter que deve assumir o grupo: uma visão compartilhada sobre o seu horizonte de êxito a alcançar.

\section{REFERÊNCIAS}

BOURDIEU, P. El sentido práctico. Buenos Aires: Siglo XXI Editores, 2007.

CALLOWAY, C. Autorregulación de los colectivos autogestivos de trabajadores/ as. Revista Idelcoop, Buenos Aires, n. 218, p. 11-30, mar. 2016. Disponível em: https://www.idelcoop.org.ar/revista/218/autorregulacion-colectivos-autogestivostrabajadoresas. Acesso em: 28 nov. 2021.

CERIONI, C. Venerado lá fora, questionado no Brasil: o legado do educador Paulo Freire. Exame, São Paulo, maio 2019. Disponível em: https://exame.abril.com.br/brasil/ paulo-freirevenerado-la-fora-exilado-no-brasil-a-trajetoria-do-educador-paulo-freire/. Acesso em: 1 fev. 2020.

ELISALDE, R. Bachilleratos populares y Autogestión educativa. Perspectivas y desafíos para la construcción de un Movimiento Pedagógico en la EDJA. In: ELISALDE, R.; DAL RI, N. M.; AMPUDIA, M.; FALERO, A. (Orgs.). Movimientos sociales, educación popular y trabajo autogestionado en el cono sur. Buenos Aires: Editorial Buenos Libros, 2013.p. 9-30.

FIGARI, C. Hegemonía empresarial y mediaciones pedagógicas en los espacios de trabajo. Sociología del Trabajo, Madrid, 2013. Disponível em: https://recyt.fecyt.es/ index.php/sociologiatrabajo/article/view/54775. Acesso em: 28 nov. 2021.

FIGARI, C. Corporaciones y dispositivos pedagógicos: la estrategia formadora del capital. Revista Estudios Sociológicos, México, v. 98, n. 33, p. 285-310, 2015. Disponível em: http://www.scielo.org.mx/pdf/es/v33n98/2448-6442-es-33-98-00285. pdf. Acesso em: 28 nov. 2021.

FREIRE, P. Pedagogy of hope: reliving pedagogy of the oppressed. London: Bloomsbury Academic, 2014.

FREIRE, P. Pedagogia do oprimido. Rio de Janeiro: Paz e Terra, 1987.

FREIRE, P. Pedagogia do oprimido. Rio de Janeiro: Paz e Terra, 2005.

G1. Só um livro brasileiro entra no top 100 de universidades de língua inglesa. G1, 17 fev. 2016. Disponível em: http://g1.globo.com/educacao/noticia/2016/02/so-umlivro-brasileiro-entra-no-top-100-de-universidades-de-lingua-inglesa.html. Acesso em: 01 fev. 2020.

HOLANDA, S. B. Raízes do Brasil. São Paulo: Companhia das Letras, 1995.

MACEDO, D. Introduction - to the 30th anniversary ed. In: FREIRE, P. Pedagogy of the oppressed. New York: Continuum International Publishing Group, 2005.p.11-28. 
OLIVEIRA, M. M. Florestan Fernandes. Recife: Editora Massangana, 2010. ORTEGA, P. Bolsonaristas não querem Paulo Freire patrono da educação. Estado de São Paulo, São Paulo, maio. 2019. Disponível em: https://politica.estadao.com.br/ blogs/fausto-macedo/bolsonaristas-nao-querem-paulo-freire-patrono-da-educacao/. Acesso em: fev. 2020.

QUIJANO,A.Colonialidad del poder, eurocentrismo y América Latina. In: CLÍMACO D. A. (Org.). Cuestiones y horizontes: de la dependencia histórico-estructural a la colonialidad/descolonialidad del poder. Buenos Aires: CLACSO, 2014. p. 285-327.

RAMALHO, R. R. Movimientos sociales y estrategias formativas: el caso de la Universidad de los Trabajadores de la Fábrica Autogestionada IMPA. Maurícias: Editorial Académica Española, 2019.

RAMALHO, R. Convergências pedagógicas entre Gramsci, Paulo Freire e Ferreriguardia - pesquisa sobre a escola libertaria. Revista Competência, Porto Alegre, v. 4, n. 2, p. 61-78, 2011. http://doi.org/10.24936/2177-4986.v4n2.2011.72

SANTOS, B. S. Descolonizar el saber, reiventar el poder. Montevideo: Trilce Editora, 2010.

TORRES, A. C. Prácticas educativas en movimientos sociales de América Latina. Revista Folios, Bogotá, n. 46, p. 3-14, 2017. Disponível em: http://doi.org/10.17227/ 01234870.46folios3.14. Acesso em: 28 nov. 2021.

ZIBECHI, R. Los movimientos sociales latinoamericanos: tendencias y desafíos. OSAL, Observatorio Social de América Latina, Buenos Aires, n. 9, p. 185-188, jan. 2003. Disponível em: http://bibliotecavirtual.clacso.org.ar/ar/libros/osal/osal9/zibechi. pdf. Acesso em: 28 nov. 2021.

\section{SOBRE O AUTOR}

Ramon Rodrigues Ramalho é doutor em ciências sociais pela Universidad de Buenos Aires (Argentina).

E-mail: ramon.rodrigues.ramalho@gmail.com

Conflitos de interesse: $\mathrm{O}$ autor declara que não possui nenhum interesse comercial ou associativo que represente conflito de interesses em relação ao manuscrito.

Financiamento: $\mathrm{O}$ estudo não recebeu financiamento.

Recebido em 3 de julho de 2020

Aprovado em 9 de abril de 2021

(C) 2022 Associação Nacional de Pós-Graduação e Pesquisa em Educação - ANPEd Este é um artigo de acesso aberto distribuído nos termos de licença Creative Commons. 